\section{LETTERS TO THE EDITOR}

Influence of metronidazole resistance on efficacy of quadruple therapy for Helicobacter pylori eradication

EDIToR,- - van der Hulst and colleagues (Gut 1998;42:166-9) suggest that apparent metronidazole resistance predicts response to antihelicobacter therapy regimens containing this antibiotic. However, the cure rate with their regimen of omeprazole, bismuth, tetracycline, and metronidazole for one week was only $90 \%(74 / 82)$. This is different from previous reports of this regimen given for seven or 12 days when 97 to $98 \%$ eradication rates were reported, and clearly antibiotic resistance was not a factor. ${ }^{1-3}$

Perhaps the answer lies in the technique used to estimate metronidazole resistance. It seems likely that unless an anaerobic phase is incorporated into the incubation, potentially misleading results may be obtained. ${ }^{45}$

Locally an apparent $19 \%$ metronidazole resistance rate found in an entirely microaerophilic culture fell to only $2 \%$ when an anaerobic phase was incorporated in the incubation in line with the suggestion of the manufacturer of the E-test system. ${ }^{5}$ This correlates well with our $97 \%$ eradication rate in Helicobacter pylori urease positive patients with spontaneous duodenal ulcer treated with a regimen of lansoprazole, tetracycline, clarithromycin, and metronidazole, the antibiotics being given for one week.

Encouraging results can be obtained with vigorous regimens if the right drug combination is selected, but laboratory studies may not be as helpful as they first appear.

M C BATESON Bishop Auckland General Hospital, Cockton Hill Road, Bishop Auckland, County Durham DL14 6AD, UK

1 de Boer W, Driessen W, Jansz A, et al. Effect of acid suppression on efficacy of treatment for Helicobacter pylori infection. Lancet 1995;345: 817-20.

2 Borody TJ, Andrews P, Fracchia G, et al. Omeprazole enhances efficacy of triple therapy in eradicating Helicobacter pylori. Gut 1995;37: 477-81.

3 Walt RP. Metronidazole-resistant H. pylori - of questionable clinical importance. Lancet 1996; 348:489-50.

4 van Zwet AA, Thijs JC, de Graaf B. Explanations for high rates of eradication with triple therapy using metronidazole in patients harbouring metronidazole-resistant Helicobacte pylori strains. Antimicrob Agents Chemother 1995;39:250-2

5 Bateson MC, Winn G, Ahmad F. Sensitivity of Helicobacter pylori to metronidazole. Eur Cancer Prev 1997;6:300-2.

6 Bateson MC, Diffey BL. Improving management of duodenal ulcer disease. Postgrad Med $\mathcal{F}$ 1997;73:717-19.

\section{Reply}

EDIToR,-We thank Dr Bateson for his comments on our paper. Dr Bateson doubts that the lower eradication rate (compared with his studies and those by others from the Netherlands) observed in our patient population correlates with a higher prevalence of metronidazole resistant Helicobacter pylori because of the possible use of inappropriate methodology to assess metronidazole sensitivity.
However, in our study $H$ pylori eradication rates of $98 \%$ were achieved in patients infected with metronidazole susceptible strains. These results are similar (even superior) to those from the cited Dutch studies which were conducted in areas with a low prevalence of metronidazole resistance (at that time around $3 \%$, assessed by the same method as in our study). By contrast, in those patients who were infected with metronidazole resistant strains, eradication efficacy was significantly lower at $82 \%$. In addition, Dr Bateson used a different quadruple regimen to that used in the Dutch studies, using clarithromycin instead of bismuth. The clarithromycin containing quadruple regimen might be more effective than the bismuth one, making comparison of efficacy difficult, if not impossible.

Dr Bateson comments that incorporation of an anaerobic phase into the incubation may lead to a drop in the frequency of metronidazole resistance. However, we do not know the clinical relevance of this in vitro phenomenon.

$$
\begin{array}{r}
\text { R W M VAN DER HULST } \\
\text { A HOMAN } \\
\text { G N J TYTGAT } \\
\text { Department of Gastroenterology, } \\
\text { Academic Medical Centre, } \\
\text { Meibergdreef } 9, \\
1105 \text { AZ Amsterdam, } \\
\text { The Netherlands } \\
\text { A VAN DER ENDE } \\
\text { P ROORDA } \\
\text { J DANKERT } \\
\text { Department of Medical Microbiology, } \\
\text { Academic Medical Centre, } \\
\text { Meibergdreef } 9, \\
\text { 1105 AZ Amsterdam, } \\
\text { The Netherlands }
\end{array}
$$

The buried bumper syndrome: a complication of percutaneous endoscopic gastrostomy

EDITOR,- - We would like to bring to attention a complication of percutaneous endoscopic gastrostomy (PEG) that presented in two patients in one afternoon. Both patients were male, and they had both had a Fresenius PEG tube placed two years previously. One patient was 88 years old with a history of stroke who, although fully alert, was unable to swallow safely. The PEG had allowed him to be cared for in his own home. The second case was that of a young man who had developed subacute sclerosing panencephalitis in 1985 following measles infection at the age of 13 . His general condition was gradually deteriorating, and he was being looked after in his own home by his family and carers.

In both cases, the Fresenius PEGs had been placed in the standard manner. The carers of the patients had followed the instructions that accompany the device without difficulty until a few weeks before presentation when they reported intermittent blockage of the tubes. On examination, the stoma site was healthy, but at endoscopy in both cases, we were unable to see the bumper (internal flange). Instead, there was a raised mound of oedematous gastric mucosa with a central small crevice, resembling a leiomyoma. Fluid could be injected under pressure through the PEG into the gastric lumen through this crevice. Radiological screening of the first case did not show any twist or disruption to the PEG tube, but the internal bumper had eroded into the anterior abdominal wall and there was a small cavity apparent between the bumper and the gastric mucosa. In both cases, a second PEG was placed in parallel to the first one without difficulty, and the first PEG was left in situ for a short period of time. Subsequently, in the first case the initial PEG was removed under local anaesthesia because it continued to discharge pus. In the second case, the patient died six weeks later from unrelated causes.

The literature records several cases of the buried bumper syndrome, and describes various methods of dealing with this complication. ${ }^{1-3}$ In our cases, it is likely that this complication occurred because of excessive pressure on the internal bumper as a result of over tightening of the external flange. However, to prevent this occurring we suggest that at regular intervals the external flange is loosened and the PEG is pushed in and out to ensure that the internal bumper moves freely. Then the external flange should be retightened sufficiently to hold the PEG in place, but not so tight as to encourage the bumper to become embedded. It is worth noting that these instructions are different from those that should be followed in the immediate period after PEG placement. In the first 48 hours, a reasonably firm pressure between the internal and external flanges should be maintained in order to prevent intraperitoneal leakage. This change in emphasis may be a source of confusion.

The instruction leaflet with the Fresenius tube does not indicate that the PEG should be able to move in and out when the external flange is loosened for skin care, and is therefore inadequate. As a result, we have surveyed the instruction leaflets provided by eight manufacturers of PEGs and found similar inadequate details in five. We have surveyed all our patients $(n=20)$ with long term PEGs and no others have developed this complication.

We therefore recommend that the correct advice is given to those caring for patients with long term PEGs to prevent this complication from occurring and that manufacturers' leaflets should mention this potential complication.

\section{R SHEERS S CHAPMAN Department of Medicine, Glan Clwyd Hospital, Rhyl, Denbighshire LL18 5UF, UK}

1 Boyd JW, DeLegge MH, Shamburek RD, et al. The buried bumper syndrome: a new technique for safe, endoscopic PEG removal. Gastrointest Endosc 1995;41:508-11.

2 Schapiro GD, Edmundowicz SA. Complications Schapiro GD, Edmundowicz SA. Complications
of percutaneous endoscopy gastrostomy. Gastrointest Endosc Clin North Am 1996;6:409-22.

3 Collure DW, Bumpers HL, Hoover EL. A complication of T-fasteners in percutaneous endoscopic gastrostomy (PEG) placement. Surg Endosc 1996;10:938-9.

\section{Screening young people for gastric} cancer

EDITor,-We read with interest the paper by Christie et al (Gut 1997;41:513-17) discussing screening of patients for gastric cancer below the age of 55 in the context of an open access endoscopy service. Based on their data the authors suggest that gastric cancer is rare below the age of 55 and presents with suspicious symptoms and signs in the overwhelming majority of cases. Thus they advocate a lower age limit of 55 for screening "uncomplicated" dyspepsia.

There are however a number of fundamental flaws in the design and interpretation of 
this study. The data are retrospective and incomplete and based on the study of only 25 patients (the under 55 group) out of 319 with gastric cancer. There is no comparison of this group with the remaining 296 patients over 55 with regard to pattern of presentation or symptoms.

Perhaps more importantly there is no mention of the number of patients who actually presented for endoscopy or were picked up on the open access service. Surely the only way to set protocols for this service would be to analyse the data from it. In contrast this study seems merely to describe 25 patients below the age of 55 presenting in the Gloucester region, drawn from a pathology database, most of whom had advanced gastric cancers.

We would hope that better awareness of the importance of early referral and increased use of diagnostic endoscopic facilities should result in more patients of all ages presenting with early disease. Based on our experience and that of centres such as Leeds, ${ }^{2}$ we would advocate open access endoscopy in anyone with new dyspeptic symptoms over the age of 40.

Finally and perhaps most worryingly the authors state in their discussion that early detection does not necessarily mean improved survival. Those of us involved in the treatment of gastric cancer realise that the only significant factor that is going to improve survival from this disease is early detection and treatment. There is overwhelming and irrefutable evidence to support this. In the UK the detection and treatment of early gastric cancers has led to a five year survival rate of over $90 \%$ in these patients. ${ }^{3}$ In Japan, where mass radiological screening of the over 40 s, ready access to endoscopy and population awareness of the disease has meant detection of early gastric cancer in more than half of all gastric cancer cases and again a five year survival of over $90 \%$ in these patients. Early detection does mean improved survival

Until we have adequate prospective data from a large open access endoscopy unit we cannot agree with the interpretation and findings of this study and urge other centres to continue to endoscope symptomatic patients under the age of 55

D KARAT

J WAYMAN

N HAYES

$S$ A RAIMES $S$ M GRIFFIN

Northern Oesophago-gastric Cancer Unit, Royal Victoria Infirmary, Queen Victoria Road,

Newcastle upon Tyne NE1 4LP, UK

1 O'Hanlon DM, Karat D, Hayes N, et al. Open access endoscopy facilitates early diagnosis of malignant and pre-malignant lesions of the stomach and oesophagus [abstract]. Gut 1995;37(suppl 2):A35.

2 Sue-Ling HM, Johnston D, Martin IG, et al. Gastric cancer: a curable disease in Britain. Gastric cancer: a cur

3 Sue-Ling HM, Martin I, Griffiths J, et al. Early gastric cancer; 46 patients treated in one surgigastric cancer; 46 patients treated in one
cal department. Gut 1992;33:1318-22.

cal department. Gut 1992;33:1318-22.
4 Hisamichi S. Screening for gastric cancer. World f Surg 1989;13:31-7.

\section{Reply}

EDIToR,-Most of the arguments raised by Karat and colleagues were covered in our paper. However, because we consider that the epidemiological principles underlying our paper are important, we think it is worth reiterating them.

The data are retrospective but there are no comparable prospective data. Unlike other studies ours was of a defined population based on postcodes. The importance of this for determining presentation characteristics and natural history of disease cannot be overemphasised. Most other studies emanate from referral centres that receive selected patients. The resulting referral bias invariably influences the type of patient seen and interpretations made. Thus we believe our study is a better reflection of the real world.

We went to great lengths to ensure completeness (e.g. searching several databases) of patient capture. Our incidences are comparable to OPCS data and therefore we think it unlikely that many, if any, patients were missed. The small number $(25$ in seven years) of patients aged less than 55 just emphasises how rare the disease is in this age group.

Karat $e t a l$ advocate better awareness of the importance of early referral to improve the chance of finding early disease. A point we stressed in our paper was that referral by general practitioners and subsequent investigation were not significantly delayed.

We did not determine the source of patients (clinic or open access) because general practitioners use clinic referrals rather than open access endoscopy for all sorts of reasons unrelated to symptoms. There would be too many confounders to make a meaningful exploration of differences in these groups. The point about the open access service in Gloucester is that it has been in operation for 20 years. The local doctors are relatively experienced in its use. The experience of its effects in the past 10 years in our district is relevant to experience in the next 10 years in other districts (the majority) that have introduced an open access service more recently.

In the UK there is no "overwhelming and irrefutable evidence" that early detection improves survival from gastric cancer. Only a randomised controlled trial can give this level of certainty and none has been done in the UK. The case series quoted from Leeds was not based on a geographically defined population and it is subject to the biases of all screening and early detection studies: lead and length bias.

We can sympathise with the sentiments of Karat et al: watching patients with gastric cancer die when intuitively you believe an earlier diagnosis would have helped is not easy. However, we would urge them to consider the following questions. Is there evidence that patients with curable gastric cancer are more likely to have uncomplicated dyspepsia than age and sex matched controls? If not, why investigate on the basis of symptoms? What opportunities are missed (e.g. early detection of colorectal cancer) if a huge amount of diagnostic resource is directed towards detecting the small number $(<200$ per annum) of gastric cancers in the under 55s. Could we use our limited financial resource in a more effective way?

$$
\begin{array}{r}
\text { R VALORI } \\
\text { N A SHEPHERD } \\
\text { Gloucestershire Royal Hospital, } \\
\text { Great Western Road, } \\
\text { Gloucester GL1 3NN, UK }
\end{array}
$$

\section{Activation of NFKB in inflammatory bowel disease}

EDITOR,-In their recent paper (Gut 1998;42:477-84) Schreiber and coworkers demonstrated that RelA (p65) is present in nuclear extracts of biopsy specimens or lamina propria mononuclear cells from patients with active inflammatory bowel disease (IBD). Furthermore, they show NFKB binding activity and a corresponding decrease in I $B \alpha$ in lamina propria mononuclear cells treated with lipopolysaccharide (LPS). In contrast, treatment with dexamethasone prevented LPS induced nuclear translocation of $\mathrm{NF} \kappa \mathrm{B}$ due to persistence of $\operatorname{I} \kappa \mathrm{B} \alpha$. The authors conclude from these data that corticosteroids inhibit NFKB activation in vitro by stabilising the cytosolic inhibitor $\mathrm{I} \kappa \mathrm{B} \alpha$ against activation induced degradation.

Firstly, this conclusion cannot be drawn from the data presented in the paper. Secondly, their conclusion contradicts a number of previously published observations.

Two models of corticosteroid mediated $\mathrm{NF \kappa B}$ inhibition have been proposed. The first proposes that down modulation of $\mathrm{\kappa B}$ driven genes results from a physical interaction between the glucocorticoid receptor and the RelA (p65) subunit. Negative cross-talk between the glucocorticoid receptor and RelA is due to direct interaction via the Rel homology domain of RelA and the DNA binding domain of the glucocorticoid receptor in combination with interference by the transactivation domain of RelA with the transcriptional activity of the glucocorticoid receptor. ${ }^{1-5}$

The second model proposes that the inhibitory effect of glucocorticoids is mediated by the induction of the I $\mathrm{KB} \alpha$ protein, which traps activated $\mathrm{NF \kappa B}$ in inactive cytoplasmic complexes. It has been shown that dexamethasone induces transcriptional upregulation of the I $\mathrm{B} \mathrm{B} \alpha$ gene, although a glucocorticoid responsive element has not been identified in the I $\mathrm{B} \alpha \alpha$ promoter. Thus, in the presence of dexamethasone, released NFKB quickly reassociates with newly synthesised I $\mathrm{B} \alpha$ which results in notably reduced amounts of NFKB that translocates to the nucleus. ${ }^{6-7}$

So far there is no evidence that steroids stabilise Iк $\mathrm{B} \alpha$. However, we have recently shown that sulphasalazine interferes with I $\mathrm{B} \alpha$ phosphorylation and proteasome dependent degradation of $\operatorname{I\kappa B} \alpha$ in vitro. ${ }^{8}$ Therefore, the available data point towards different levels of interference with $\mathrm{NF \kappa B}$ activation by sulphasalazine and corticosteroids.

R M SCHMID G ADLER Department of Internal Medicine I, University of Ulm, Ulm, Germany S LIPTAY Department of Paediatrics, University of Ulm, Ulm, Germany

Correspondence to: Correspondence to: $\mathrm{Dr}$ Schmid, Department of Internal Medicine I, University of Ulm, Robert-Koch-Strasse 8, 89081 Ulm, Germany.

1 Caldenhoven E, Liden J, Wissink S, et al. Negative cross-talk between RelA and the glucocorticoid receptor: a possible mechanism for the anti-inflammatory action of glucocorticoids. Mol Endocrinol 1995;9:401-12.

2 Ray A, Prefontaine KE. Physical association and functional antagonism between the p65 subunit of transcription factor NF-kappa B and the glucocorticoid receptor. Proc Natl Acad Sci USA 1994;91:752-6.

3 Scheinman RI, Gualberto A, Jewell CM, et al. Characterization of mechanisms involved in transrepression of NF-kappa B by activated glucocorticoid receptors. Mol Cell Biol 1995; 15:943-53.

4 Wissink S, van Heerde EC, Schmitz ML, et al. Distinct domains of the RelA NF- $\kappa B$ subunit are required for negative cross-talk and direct 
interaction with the glucocorticoid receptor. $\mathcal{F}$ Biol Chem 1997:272:22278-84.

5 De Bosscher K, Schmitz ML, van den Berghe W, et al. Glucocorticoid-mediated repression of nuclear factor- $\mathrm{kB}$-dependent transcription involves direct interference with transactivation. Proc Natl Acad Sci USA 1997;94:13504-9.

6 Scheinman RI, Cogswell PC, Lofquist AK, et al. Role of transcriptional activation of I $\mathrm{KB} \alpha$ in mediation of immunosuppression by glucocorticoids. Science 1995;270:283-6.

7 Auphan N, DiDonato JA, Rosette C, et al. Immunosuppression by glucocorticoids: inhibition of NFKB activity through induction of IאB synthesis. Science 1995;270:286-90.

8 Wahl C, Liptay S, Adler G, et al. Sulfasalazine: a potent and specific inhibitor of nuclear factor kappa B. F Clin Invest 1998;101:1163-74.

\section{Reply}

EDITOR,-We appreciate the comments by Schmid and colleagues which address important aspects of the cellular mechanisms involved in the in vitro regulation of $\mathrm{NF}_{\mathrm{K}} \mathrm{B}$ activation. Our sequential publications in $G u$ have tackled the clinical importance of the in vivo activation of the proinflammatory transcription factor $\mathrm{NF} \kappa \mathrm{B}$ in inflammatory bowel disease (IBD). We have also shown the importance of human granulocytes in primary cultures as specific contributors to this process. ${ }^{12}$ These studies were not designed to investigate the cellular mechanism of steroid action in the NFKB system, but rather to look at important clinical aspects of $\mathrm{NF} \kappa \mathrm{B}$ activation and steroid treatment in Crohn's disease.

An important anti-inflammatory mechanism in steroid action is the inhibition of $\mathrm{NF} \kappa \mathrm{B}$ activation. ${ }^{34}$ It has been suggested that this mechanism involves the induction of $\mathrm{I} \kappa \mathrm{B} \alpha$ expression, the stabilisation of $\mathrm{I} \kappa \mathrm{B} \alpha$ (resulting in sequestration of $\mathrm{NF \kappa B}$ in the cytoplasm) and protein-protein interactions between $\mathrm{NF} \kappa \mathrm{B}$ and the glucocorticoid receptor, leading to inhibition of transactivation. ${ }^{5}$

The exact mechanisms leading to the steroid induced persistence of $\mathrm{I} \kappa \mathrm{B} \alpha$ protein are not established. Although some experiments have shown upregulation of the expression of $\mathrm{I} \kappa \mathrm{B} \alpha$ by steroids, as those cited by Schmid $e$ $a l$, these findings have not been reproduced in more recent studies. $^{6-8}$ In addition, the glucocorticoid-like immunosuppressive effect of oestrogen as well as other steroid hormones is also attributed to stabilisation of the $\mathrm{I} \kappa \mathrm{B} \alpha$ protein as a result of inhibition of $\mathrm{I} \kappa \mathrm{B} \alpha$ degradation. ${ }^{9}$ The kinetics of I $\mathrm{B} \mathrm{B} \alpha$ degradation in human granulocytes are very rapid and steroid induced protection of the $I \kappa \mathrm{B} \alpha$ protein is seen within minutes. One may therefore speculate how much induction of expression and how much stabilisation against degradation may contribute to the rapid time course in granulocytes. The relative contribution of these mechanisms to the clinical efficacy of steroids in inhibiting activation of $\mathrm{NF \kappa B}$ needs to be evaluated in future studies.

Taken together, the understanding of the role of $I \kappa B \alpha$ in steroid induced suppression of $\mathrm{NF} \kappa \mathrm{B}$ activation is hampered by conflicting findings which may partly result from the stimulatory conditions chosen. The choice of the cell system (i.e. epithelial carcinoma cell lines which often have an altered $\mathrm{I} \kappa \mathrm{B} \alpha / \mathrm{NF} \kappa \mathrm{B}$ system versus primary $\operatorname{cells}^{10}$ ) may also confound these data.

Schmid et al also discuss the mechanism of the anti-inflammatory action of sulphasalazine. ${ }^{11}$ They propose that treatment with sulphasalazine results in the inhibition of I $\mathrm{B} \alpha$ degradation, whereas aminosalicylates (5-ASA) or sulphapyridin have no effect on
NFאB activation. ${ }^{11}$ The authors' findings, which have been obtained in colonic carcinoma (SW620) and Jurkat T cell lines, add an important aspect to the mechanisms of action of anti-inflammatory drugs in IBD but also underline the importance of the experimental system investigated as discussed earlier. In other systems (e.g. primary monocyte cultures) aminosalicylates also seemed to inhibit the activation of $\mathrm{NF} \kappa \mathrm{B}$ via inhibition of $\mathrm{I} \kappa \mathrm{B} \alpha$ degradation. ${ }^{12-18}$

Activation of $\mathrm{NF \kappa B}$ may be a central element in the pathophysiology of Crohn's disease. Inhibition of $\mathrm{NF \kappa B}$ activation offers an attractive hypothesis for the action of numerous drugs with clinically relevant effects in IBD. The exact mechanisms involved have yet to be determined in the relevant cell systems and in further ex vivo studies using affected tissues of diseased patients.

S SCHREIBER

$S$ NIKOLAUS

J HAMPE

First Medical Department, Christian Albrechts University, Schittenhelmstrasse 12, 24105 Kiel, Germany email:s.schreiber@mucosa.de

1 Schreiber S, Nikolaus S, Hampe J. Activation of nuclear factor $\mathrm{KB}$ in inflammatory bowe disease. Gut 1998;42:477-84

2 Nikolaus S, Bauditz J, Gionchetti P, et al. Increased secretion of pro-inflammatory cytokines by circulating polymorphonuclear neutrophils and regulation by interleukin 10 during intestinal inflammation. Gut 1998;42:

3 Ray A, Prefontaine KE. Physical association and functional antagonism between the p65 subunit of transcription factor NF-kappa B and the
glucocorticoid receptor. Proc Natl Acad Sci glucocorticoid recept

4 Scheinman RI, Cogswell PC, Lofquist AK, et al. Role of transcriptional activation by IKB in mediation of immunosuppression by glucocorticoids. Science 1995;270:283-6.

5 Wissink S, van Heerde EC, van der Burg B, et al. A dual mechanism mediates repression of NF- $\mathrm{BB}$ activity by glucocorticoids. Mol Endocrinol 1998;12:355-63.

6 Brostjan C, Anrather J, Csizmadia V, et al. Glucocorticoid-mediated repression of NFKB activity in endothelial cells does not involve

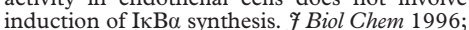
271:19612-16.

7 De Bosscher K, Scmitz ML, van den Berghe W, et al. Glucocorticoid-mediated repression of nuclear factor-kappaB-dependent transcripnuclear factor-kappaB-dependent transcripvation. Proc Natl Acad Sci USA 1997;94: vation. $P$.

8 Heck S, Bender K, Kullmann M, et al. I $\kappa \mathrm{B} \alpha$-independent downregulation of NF- $\kappa \mathrm{B}$ activity by the glucocorticoid receptor. $E M B O$ f 1997; 16:4698-707.

9 Sun WH, Keller ST, Stebler BS, et al. Estrogen inhibits phorbol ester-induced I $\kappa \mathrm{B} \alpha$ transcription and protein degradation. Biochem Biophys Res Commun 1998;244:691-5.

10 Jobin C, Haskill S, Mayer L, et al. Evidence for altered regulation of $\mathrm{I} \kappa \mathrm{B} \alpha$ degradation in human colonic epithelial cells. F Immunol 1997;158:226-34.

11 Wahl C, Liptay S, Adler G, et al. Sulfasalazine: a potent and specific inhibitor of nuclear factor potent and specific inhibitor of nuclear fact
kappa B. F Clin Invest 1998;101:1163-74.

12 Kopp E, Ghosh S. Inhibition of NF-кB by sodium salicylate and aspirin. Science 1994; 265:956-9.

13 Bitko V, Velazquez A, Yang L, et al. Transcriptional induction of multiple cytokines by human respiratory syncytial virus requires activation of NF- $\mathrm{\kappa B}$ and is inhibited by sodium salicylate and aspirin. Virology 1997;232:36978 .

14 Stange C, Ramirez I, Gomez I, et al. Phosphorylation of nuclear proteins directs binding to salicylic acid responsive elements. Plant $\mathcal{f}$ 1997;11:1315-24.

15 Oeth P, Mackman N. Salicylates inhibit lipopolysaccharide-induced transcriptional activation of the tissue factor gene in human monocytic cells. Blood 1995;86:4144-52.

16 Takashiba S, Van Dyke TE, Shapira L, et al. Lipopolysaccharide-inducible and salicylate, sensitive nuclear factor (s) on human tumor necrocis factor alpha promoter. Infect Immun 1995;63:1529-34.

17 Pierce JW, Read MA, Ding H, et al. Salicylates inhibit I $\mathrm{B} \alpha$ posphorylation, endothelialleukocyte adhesion molecule expression, and neutrophil transmigration. F Immunol 1996; 156:3961-9.

18 Schwenger P, Alpert D, Slotnik EY, et al. Activation of p38 mitogen-activated protein kinase by sodium salicylate leads to inhibition of tumor necrosis factor-induced $I \kappa B \alpha$ phosphorylation and degradation. Mol Cell Biol 1998;18:78-84.

\section{BOOK REVIEWS}

Pancreatitis. Lankisch PG, Banks PA. (Pp 377; illustrated; f57.00.) Berlin: Springer-Verlag, 1998. ISBN 3-540-61726-4.

This book will be a bench mark by which others on the subject of pancreatitis will be judged. This is no ordinary volume assembled by two hard-pressed editors from an array of international experts with differing styles and experience but a text written solely by two eminent authors. The gestation period was 10 years, the evidence base is 1900 citations and the bias is distinctly clinical-that is, this is a reference book for the working gastroenterologist (surgeon or physician), not a text littered with incomprehensible molecular biology.

The two diseases, acute and chronic pancreatitis, are dealt with in a similar format, beginning with classification, aetiology, pathology, and epidemiology, progressing to the clinicians' holy grail: diagnosis and treatment. Herein lies the book's strength. There is no artificial segregation into separate sections by a radiologist, an endoscopist or a surgeon, but an integrated and detailed overview giving practical guidance. For two disease processes whose pathogenesis is poorly understood and for which there are few specific therapies, it is obviously necessary for guidance to be more than anecdotal. Thus, where there is controversy the literature has been carefully sifted through, debated and a bottom line recommendation reached. The approach is not nihilistic, but thoroughly positive in its analysis of international efforts to solve the conundrum of pancreatitis.

So what gems can be extracted to whet your appetite? Firstly a riveting discussion of scoring systems and prognostic signs in acute pancreatitis, a topic which often switches off the relative newcomer to this area but which holds the key to stratification for current or new treatment options. Ranson, Imrie and APACHE II take on a new life, liberally illustrated with explanatory figures and tables. Secondly, there is a clear and detailed discussion of the merits and practical value of the various pancreatic function tests which can be used in chronic pancreatitis. When to use each one, sensitivity and specificity, and practical tips bring clarity to an often muddled area. And on the back of this come recommendations for intervention and treatment. In my opinion the chapters on treatment cannot be bettered. Finally, although the authors are both physicians the surgical options available are debated sensibly and concisely and placed in a realistic perspective. 
Any doctor treating patients with pancreatitis can be recommended to buy and enjoy this exceptional book.

\section{A N KINGSNORTH}

Current Studies in Haematology and Blood Transfusion. Volume 62. Hepatitis C Virus. 2nd edition. Edited by Reesink HW. (Pp 270; \$172.25.) Basel: Karger, 1998. ISBN 3-8055-6542-9.

In just under a decade since the hepatitis C virus was first discovered the proliferation of research publications has been overwhelming. Although this is an appropriate reflection of the prevalence and clinical importance of the disease it has unfortunately created a confusing situation for clinicians and scientists outside the field. As a hepatologist I tend to feel that hepatitis $\mathrm{C}$ virus belongs in my domain but in reality, of course, the virus impacts on a number of medical specialists. It should not therefore have been a complete surprise to encounter a book on the subject which is part of a series on haematology and blood transfusion.

The editor of this book has assembled a strong field of contributors who are recognisably experts on the areas which they have been asked to review. The selection of topics is comprehensive and covers everything from molecular biology and immunology to natural history and treatment.

In order to justify my free copy of the book I feel that it is necessary to point out some minor criticisms. Given the high prevalence of this infection and its variable outcome, I felt that the chapter on natural history of infection could have been a bit longer. I also feel that although the summaries of clinical trials are thorough it would have been helpful to have included, at the end of the treatment chapter, a recommendation on best current clinical practice. Of course I realise that this is changing all the time but as this book is already on its second edition we presumably can expect an update in reasonable time.

As I mentioned before this book is concise and comprehensive. This combination usually implies that it would also be unreadable but this is not the case. Inevitably a lot of detail has been edited away from the concise summaries but this is counterbalanced by excellent referencing which guides the interested reader to key publications in the literature.

I am not really sure at whom this book was originally aimed but I have my own ideas about who would benefit from having a copy on their bookshelf. I recommend this book to the specialist registrars who are starting in the viral hepatitis clinic and to $\mathrm{PhD}$ students who are beginning their hepatitis $\mathrm{C}$ research in the laboratory. For the general gastroenterologist it would certainly provide a more accessible source of background information than other textbooks I have read.

M THURSZ

Shared Care in Gastroenterology. Travis S, Stevens R, Dalton H. (Pp 226; illustrated; $£ 22.50$.) Oxford: Isis Medical Media, 1997. ISBN 1-899066-40-6.

The relationship between general practitioners and gastroenterologists has, generally, been a better one than with most other specialists. In the UK, this has in part been due to long fostered relationships between the British Society of Gastroenterology and the Primary Care Society for Gastroenterology. Also, there is a closely shared and common clinical agenda between general practitioners and gastroenterologists. Some aspects of gastroenterology, particularly dyspepsia, are managed essentially in primary care and there is a healthy, if sometimes competitive, dialogue between the professions.

This book reflects this ethos, exploring common ground through a patient centred approach. In doing so it meets the new challenges facing clinicians through the restructuring of the NHS and the advent of the Primary Care Groups, which are likely to seek closer and more meaningful dialogue across the primary-secondary care interface. The authors, a general practitioner and two specialists, offer an intelligent entree into the concepts of shared and managed care, both of which are likely to be the basis of much future health transactions within the NHS

The authors have managed to cover the gamut of gastroenterological problems without mimicking a traditional topic based textbook. They draw upon the experiences of mixed groups of general practitioners and specialists who have discussed shared care in specific situations. The book contains copies of shared care cards and other materials of practical use-for example, for inflammatory bowel disease. Colon cancer and polyps are particularly well described with a review of management options of value from both general practice and hospital viewpoints. An early section on clinical skills is especially engaging although it might have been augmented by reference to the relatively poor predictability of clinical diagnoses. In a world of increasing use of diagnostic and referral facilities a closer examination of the uncertainty and dilemmas faced by the general practitioner would have been welcome. Many general practitioners believe that gastroenterologists rarely make clinical diagnoses at the initial consultation: they merely order tests! Equally, the authors have managed to evade a critical review of one of the most contentious areas in reflux management: whether to step "up" or "down" therapy, and the appropriateness of long term treatment with potent drugs.

This does not, however, take away from an excellent book presented in compact softback version. It is likely to appeal to the general practitioner for diagnosis and management, to the specialist registrar for easy reference and to the consultant seeking closer collaboration with primary care. It does extend beyond the basics, even has a section on patient support groups and recognises the realities of the changing environment of the NHS. It's worth buying.

P HUNGIN

Diagnosis and Treatment of Hepatocellular Carcinoma. Edited by Livraghi T, Makuuchi M, Buscarini L. (Pp 454; illustrated; price not given.) London: Greenwich Medical Media, 1997. ISBN 1-900151-308.

Very early in my career I told a senior colleague that I was interested in trying to treat patients with hepatocellular carcinoma (HCC). "Oh, that is easy," he replied, "Give them a bottle of whiskey and send them home!" In those days HCC was seldom even diagnosed during life let alone treated. Gut readers, many of whom will have been brought up on single authored textbooks of gastroenterology, may be dismayed to find that treatment and diagnosis of HCC can now fill an entire book of more than 400 pages. That this task requires more than 60 authors will compound their dismay. Indeed, it is probably the size of the book that tells the main story. There is no consensus on how best to diagnose, screen for, or treat this tumour, with the result that each diagnostic approach, and each of the numerous treatment options, is described individually by their own proponents.

This is not to imply that HCC is not worthy of such detailed examination. In high incidence areas HCC management will occupy very considerable resources. For example, about a quarter of all beds in this author's wards will be taken up by patients with HCC. In the West, the implication of the rate at which HCC develops among the increasing number of patients who are carriers of the hepatitis $\mathrm{C}$ virus (HCV) is only just sinking in. Decisions on whether or not to screen them all, and then what to do when the tumour is found, will have major resource implications for gastroenterologists and hepatologists. As noted above, gastroenterologists in the past have sought refuge in (justified) therapeutic nihilism. Now, however, it is clear that long term survival following resection can be achieved and long term results following liver transplantation are very impressive.

Within this volume the reader will be able to find information on all aspects of the diagnosis and management of HCC. The book is comprised of 32 chapters arranged in five sections: basic aspects, clinical aspects, diagnosis, treatment and fibrolamellar HCC with an international, though predominantly Italian and Japanese authorship. The individual chapters are perhaps best read as a series of good reviews on the various topics rather than constituting a coherent text book. This is because in several instances-for example, in the chapter on chemoembolisation, the authors tend to recount their own, single institution experience without reference to randomised controlled trials when these are done elsewhere.

There are some areas where tighter editing would have helped clarity and accuracy. For example, under the heading of "Besides therapies" we are told that "non-randomized trials (of tamoxifen) supplied contradictory results regarding the value of its use ..." But of the five references supplied to support this contention, three were, in fact, clearly randomised and at least two of these suggested that tamoxifen did increase survival.

Gut readers will find a good analysis (Cottone and D'Antoni), but no easy answers, as to how often and by what means to screen their high risk patients. Whether screening will help the individual or the community remains unclear. Italian authors are pessimistic, Japanese more positive. Perhaps they are both correct in relation to the tumour as seen within their own countries. The authors' conclusion that, "The lack of evidence that early detection translates into improved clinical outcome strengthens the concept that the primary goal in the battle against HCC should focus on the prevention of cirrhosis by vaccinating against hepatitis, by minimizing the risk of hepatitis $\mathrm{C}$ and decreasing the risk of alcoholism", is probably correct but likely to be of little solace to current carriers of hepatitis B or C.

With regard to an overall approach to therapy, individual units will find a great deal of information in this well produced and lav- 
ishly illustrated book. They will, however, have to sift the data very carefully to develop approaches suitable for their own institutions. The editors conclude, under the heading "Therapeutic guidelines": "To sum up, the possible combinations (of treatments) are many and it is not easy to lay down strict rules for the management of patients whose HCC is not advanced ... the most opportune treatment has to be decided in the light of each individual patient's characteristics, evaluating every variable, and the expertise available at each centre and the resources of the national health services".

It seems that HCC is not a single entity but rather several different types. Each may need its own approach, both in relation to different geographical areas of the world and to different aetiologies. This makes the task of editors wishing to give an overall view of HCC extremely difficult, but Livraghi, Makuuch and Buscarini have, by and large, succeeded.

P JOHNSON

\section{NOTES}

European Mucosal Immunology Meeting. The Cells and Molecules Important in Mucosal Tolerance and Inflammation

The European Mucosal Immunology Meeting. The Cells and Molecules Important in Mucosal Tolerance and Inflammation will be held at the Charterhouse Square Campus of St Bartholomew's and the Royal London School of Medicine and Dentistry, London, UK, on 2-3 October 1998. Further information from: Professor T T MacDonald, Department of Paediatric Gastroenterology, St Bartholomew's Hospital, London EC1A 7BE. Email: t.t.macdonald@mds.qmw.ac.uk.

\section{Laparoscopic Surgery}

A Course on Laparoscopic Surgery will be held at the University Hospital Saint Pierre, Brussels, Belgium, on 17-20 November 1998. Further information from: Conference Services S.A., Avenue de l'Observatoire 3, bte 17, B-1180 Brussels, Belgium. Email: conference.services@skynet.be.

\section{Second Inflammatory Bowel Disease Meeting}

The Second Inflammatory Bowel Disease Meeting will be held at Chester Town Hall, Chester, UK, on 23-24 November 1998. Further information from: Professor J M
Rhodes, Royal Liverpool University Hospital, Prescot Street, Liverpool L7 8XP. Tel: +44 151706 3558; Fax: +44 1517065832.

\section{3th International Workshop on Therapeutic Endoscopy}

The 13th International Workshop on Therapeutic Endoscopy will be held at the Endoscopy Centre, Prince of Wales Hospital, Hong Kong, on 1-3 December 1998. Further information from: Professor Sydney Chung, Endoscopy Centre, Prince of Wales Hospital, The Chinese University of Hong Kong, Shatin, N.T., Hong Kong. Tel: +852 2632 2233; Fax: +852 26350075

\section{European Postgraduate Gastro-Surgical School Symposia}

The 7th Course on Digestive Endoscopy Live will be held at the Academic Medical Centre, Amsterdam, The Netherlands, on 3-4 September 1998. Registration fee: NLG 450.00 .

H. pylori: from Bench to Bedside will be held at the Academic Medical Centre, Amsterdam, The Netherlands, on 24-25 September 1998. Registration fee: NLG 300.00

Minimally Invasive Surgery: A Critical Evaluation will be held at the Academic Medical Centre, Amsterdam, The Netherlands, on 13 November 1998. Registration fee: NLG 200.00 .

From Gene to Cure II: Bilio-pancreatic malignancy will be held at the Academic Medical Centre, Amsterdam, The Netherlands, on 4-5 February 1999.

Further information from: Helma Stockmann, Managing Director, European Postgraduate Gastro-Surgical School, G-4-zuid, Academic Medical Centre, Meibergdreef 9, 1105 AZ Amsterdam, The Netherlands. Tel: +31 20 566 3926; Fax: +31 205666569 or 6914858 ; Email: w.j.stockman@amc.uva.nl.

\section{Sir Francis Avery Jones BSG Research Award 1999}

Applications are invited by the Education Committee of the British Society of Gastroenterology who will recommend to Council the recipient of the 1999 Award. Applications (TWENTY COPIES) should include:

- A manuscript (2 A4 pages ONLY) describing the work conducted

- A bibliography of relevant personal publications

- An outline of the proposed content of the lecture, including title

- A written statement confirming that all or a substantial part of the work has been personally conducted in the UK or Eire.
Entrants must be 40 years or less on 31 December 1998 but need not be a member of the BSG. The recipient will be required to deliver a 40 minute lecture at the Annual Meeting of the Society in March 1999. Applications (TWENTY COPIES) should be made to the Honorary Secretary, BSG, 3 St Andrews Place, London NW1 4LB, by 1 December 1998.

34th Annual Meeting of the European Association of the Study of the Liver (EASL)

The 34th Annual Meeting of the European Association of the Study of the Liver (EASL) will be held in Naples, Italy, on 8-12 April 1999. Topics covered include: The Liver and Systemic Disorders, Infection and Liver Diseases, Gene Therapy in Liver Diseases, and Ascites, SPB, Hepatorenal Syndrome. The president of the 1999 meeting is Professor Giuseppe Giusti. EASL will offer 120 Travel Bursaries to selected young investigators and 30 to Eastern Europeans, dependent on submission of an abstract. In addition, registration is free for first authors under 35 years of age who submit abstracts. This is part of EASL's policy to encourage young investigators to attend and present at its scientific meeting. Abstract deadline: 30 November 1998. Application deadline for 1999 EASL Fellowships: 31 December 1998.

Further information from: EASL Liaison Bureau, Hepatology, Necker Hospital, 149 rue de Sèvres, 75743 Paris Cedex 15, France. Fax: +33 1444951 65; Email: isabelle.porteret@nck.ap-hop-paris.fr.

\section{Second International Workshop on Helicobacter pylori}

The Second International Workshop on Helicobacter pylori will be held in Hong Kong on 24 and 25 April 1999. Further information from: Professor Joseph Sung, Endoscopy Centre, Prince of Wales Hospital, The Chinese University of Hong Kong, Shatin, N.T., Hong Kong. Tel: +852 2632 2233; Fax: +852 2635 0075; Email: info@hksde.org.

\section{International Conference at the Hong Kong Academy of Medicine}

The Hong Kong Academy of Medicine will host its first International Conference on 26-29 November 1999. Further information from: Congress Secretariat, 9/f, Multicentre Block A, Pamela Youde Nethersole Eastern Hospital, 3 Lok Man Road, Chai Wan, Hong Kong. Tel: +852 2515 5755; Fax: +852 2505 3149; Email: hkam@hkam.org.hk; Website: http://www.hkam.org.hk. 